\title{
Morphological Assessment of the Behavior of Three-Dimensional Anionic Collagen Matrices in Bone Regeneration in Rats
}

\author{
Fúlvio B. Miguel, ${ }^{1}$ Ana Karina M. V. Cardoso, ${ }^{1}$ Aryon A. Barbosa, Jr, ${ }^{2}$ Elcio Marcantonio, Jr, ${ }^{3}$ \\ Gilberto Goissis, ${ }^{4}$ Fabiana P. Rosa ${ }^{5}$ \\ ${ }^{1}$ Master of Dentistry, Dentistry Faculty, Federal University of Bahia, Salvador (BA), Brazil \\ ${ }^{2}$ Gonçalo Moniz Research Center, Oswaldo Cruz Foundation, Salvador (BA), Brazil \\ ${ }^{3}$ Dentistry Faculty, State Paulista University, Araraquara (SP), Brazil \\ ${ }^{4}$ Chemistry Department, University of São Paulo, São Carlos (SP), Brazil \\ ${ }^{5}$ Health Sciences Institute, Federal University of Bahia, Salvador (BA), Brazil
}

Received 23 March 2005; revised 10 August 2005; accepted 9 September 2005

Published online 7 February 2006 in Wiley InterScience (www.interscience.wiley.com). DOI: 10.1002/jbm.b.30492

\begin{abstract}
The osteogenic behavior of three-dimensional collagenic and anionic matrices (M3DGA) implanted in critical bone defects of $8 \mathrm{~mm}$ diameter was morphologically assessed. The defects were performed in the calvaria of 48 adult male (Wistar) rats, and observed at days 15, 30, and 60. The animals were distributed in four groups of equal number: GA1 (M3DGA with $60 \mathrm{~min}$ of cross-linking in glutaraldehyde [GA]); GA2 (M3DGA with 30 min of cross-linking in GA); GA3 (M3DGA with 15 min of cross-linking in GA); and G4 (control group, without any implanted biomaterial). The M3DGAs were biocompatible, with mild and regressive chronic granulomatous inflammation, associated with the degradation of their fibers. Furthermore, tissue neovascularization and neomineralization was noted, with statistically significant differences in these amounts among the groups (GA1, GA2, and GA3) and G4. In G4 neoformation was limited to the edges of the defect as well as interstitial fibrosis. Under the experimental conditions and for the parameters analyzed, the M3DGAs had osteogenic behavior, which was more evident in M3DGA 15 min. () 2006 Wiley Periodicals, Inc. J Biomed Mater Res Part B: Appl Biomater 78B: 334-339, 2006
\end{abstract}

Keywords: tissue bioengineering; anionic collagen; three-dimensional matrix; bone regeneration; critical size defect

\section{INTRODUCTION}

The scientific and technological advances over the last few decades, with regard to tissue bioengineering both in vitro and in vivo, have enabled the development of new biomaterials, alternative substitutes for bone grafts, and perfecting of regenerative techniques.

Among the various natural substances that constitute the biomaterials, collagen protein stands out because it is easily found in natural tissues; it presents little immune response and low toxicity, enables adhesion, insertion and cell growth, as well as the deposition of hydroxiapathite crystals inside its structure. Moreover, it is inexpensive to prepare. ${ }^{1,2}$

However, there is a need for adding chemical and physical treatments that aim to remove or neutralize its antigenic prop-

Correspondence to: F. P. Rosa (e-mail: fabianapaim@cpqgm.fiocruz.br) (C) 2006 Wiley Periodicals, Inc. erties, enhance its mechanical properties, and consequently help to control its degradation, but without modifying its original structure. $^{3-5}$ Hydrolysis removes the interstitial cells from the native collagen matrix, adds negative electrical charges to the collagen molecules, increases the piezoelectricity, and introduces signals for controlled mineralization. ${ }^{1,6-9}$ Cross-linking in glutaraldehyde (GA) promotes the necessary links for fixing and stabilizing the functional molecules of this protein, ${ }^{3}$ favors a controlled degradation process, ${ }^{4}$ and also increases the quantity of its negative charges without promoting changes in the posi-

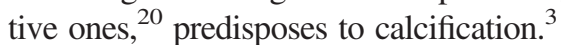

In view of this, this study aimed to make a histomorphological assessment of bone neoformation with three-dimensional collagen/elastin anionic matrix implants in critical defects.

\section{MATERIALS AND METHODS}

Bovine pericardium (BP) was obtained from animals aged 30-60 months. The collagen was prepared as described in 


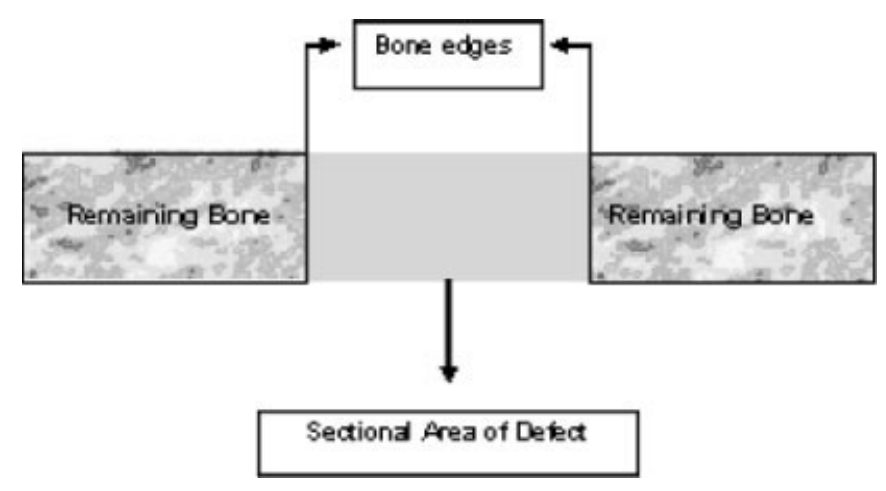

Figure 1. Sectional area of defect.

Rosa et al. ${ }^{9}$ Hydrolysis of aspargine and glutamine was characterized by titration, infrared spectroscopy, differential scanning calorimetry, light microscopy, scanning electron microscopy (SEM), and transmission electron microscopy (TEM) as described earlier in Bet et al. ${ }^{7}$ and Goissis et al. ${ }^{1}$ In our study, the collagen's cross-linking in GA was prepared as described in previous publications, ${ }^{4}$ only with differences in the cross-linking time. The materials were supplied by the Physics-Chemistry Department of the Chemical Institute at the University of São Paulo, São Carlos (SP).

After approval by the Ethical Research Committee on Animals from the Animal Experimentation Laboratory of the Dentistry Faculty of the Federal University of Bahia-UFBA, 48 male Wistar rats, weighing between 400 and $450 \mathrm{~g}$, were randomly divided into four groups of equal number: GA1 -M3DGA with $24 \mathrm{~h}$ of hydrolysis, cross-linked for $60 \mathrm{~min}$ in GA $0.05 \%$; GA2 - M3DGA with 24 h of hydrolysis, crosslinked for $30 \mathrm{~min}$ in GA $0.05 \%$; GA3 -M3DGA with $24 \mathrm{~h}$ of hydrolysis, cross-linked for $15 \mathrm{~min}$ in GA $0.05 \%$; G4 -control group (defect with no implanted biomaterial), assessed at the biological points of 15,30 , and 60 post-operative days.

The animals received anesthesia, analgesia, and sedation with an intramuscular injection of ketamine chloride $(0.08$ $\mathrm{mL} / 100 \mathrm{~g}$ of body mass) and with xilazine chloride $(0.04$ $\mathrm{mL} / 100 \mathrm{~g}$ of body mass). After they were trichotomized in the calvaria, anti-sepsis was performed and placed lying in the ventral position. The surgical technique was described by Takagi and Urist, ${ }^{10}$ in which surgical access to the posterior portion of the cranial calvaria was obtained with a bicoronal cutaneous, muscular and periosteal incision, $32 \sim 3 \mathrm{~cm}$ long. The periosteum was totally removed, exposing the bone tissue. In the middle portion of the calvaria, from the apex of the posterior cranial suture, transfixed circular bone defects of 8 mm diameter and $\sim 1 \mathrm{~mm}$ thickness were made, by complete removal of bone tissue, using a trephine milling cutter of 8 $\mathrm{mm}$ diameter, mounted at a counter angle with a reduction of 16:1, coupled to a $1500 \mathrm{rpm}$ motor for implant under constant irrigation with physiological solution.

The M3DGAs belonging to each group were implanted in the bone defects, filling them and keeping them stabilized at the implantation site by the repositioned flat and sutured with interrupted stitches of 3.0 silk thread. The control group was kept without implanting material. After the surgical procedure, the animals were kept in individual and identified metal cages.

The animals were killed at the biological points of 15,30 , and 60 post-operative days. The entire superior portion of the calvaria was removed. The specimens obtained were fixed in a $10 \%$ formalin solution and afterwards decalcified in $5 \%$ nitric acid $(72 \mathrm{~h})$. The serial histological cuts of $5 \mu \mathrm{m}$ thickness were stained with hematoxylin \& eosin (H\&E), orcein (ORCE), and Alcian blue (A.A.), and examined by optic microscopy. For morphometric assessment, the Leica Qwin Image Processing Analysis system was used. The following parameters were measured: total neoformed mineralized sectional area, linear extension of primary defect, percentage of linear filling of the defect by neoformed mineralized tissue (Figure 1 and 2). The differences between the means were assessed using the following tests: analysis of variance (ANOVA - one way), Chi-Squared -Table of contingency $\left(\chi^{2}\right), t$-Student. Considering the level of significance $\alpha=5 \%(p \leq 0.05)$.

\section{RESULTS AND DISCUSSION}

In this study, bone defects with a dimension considered to be critical for bone repair ${ }^{11}$ were also created. These characteristics were found in G4 (without filling material), in which bone neoformation occurred only reparatively and limited to the edges of the defect. These results were similar to those in the work of Takagi and Urist, ${ }^{10}$ Sweeney et al., ${ }^{12}$ and Chesmel et al. ${ }^{13}$ The defect-filling region was populated by fibroblastic cells and a deposition of fibrous connective tissue (Fig. 3). After day 15, in the central areas of the defect, more intense moderate chronic inflammation was observed. However, after day 60, this appearance was mild and regressive.

Three-dimensional scaffolds have been used extensively as biomaterials in tissue engineering research for in vitro study of cell-scaffold interactions and tissue synthesis and in vivo study for tissue and organ regeneration. This scaffolds serve as an analog of the extracellular matrix, acting as a physical support structure and as an insoluble regulator of biological activity that affects cell processes such as migra-

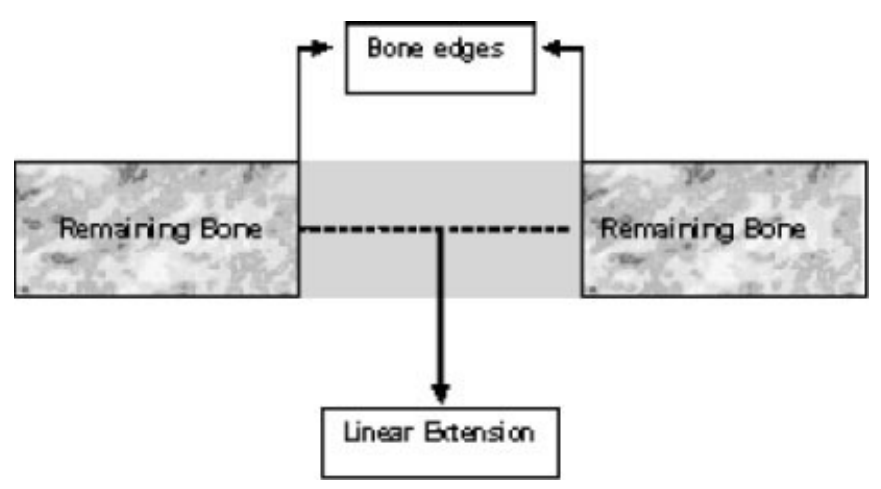

Figure 2. Linear extension of the primary defect. 


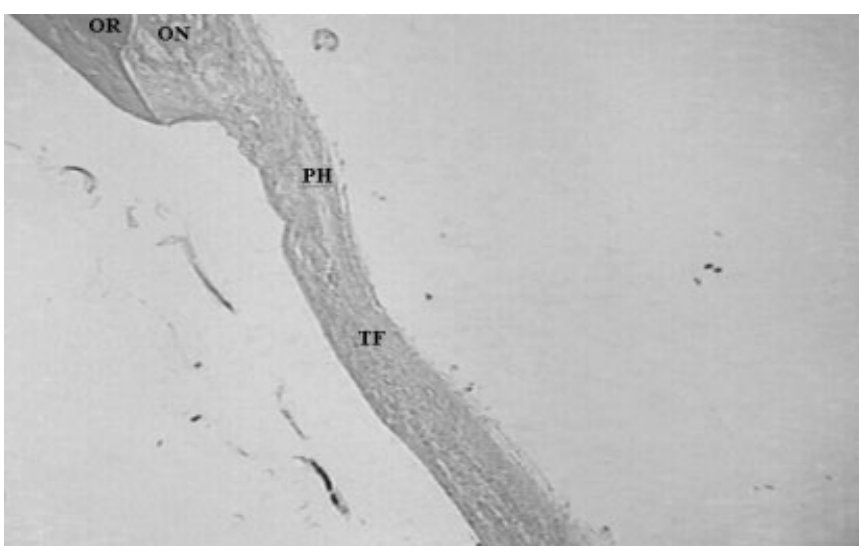

Figure 3. G4 15D. Area of the defect filled by fibrous conjunctive tissue with plates of hyalinization $(\mathrm{PH})$. Neoformed bone (ON), remaining bone (OR), fibrous tissue (TF). H.E. Final enlargement $\times 80$.

tion, contraction, division, ${ }^{14}$ and differentiation. However, according to Rosa, ${ }^{15}$ an inflammatory reaction is frequently associated with the presence of the biomaterials when they are in contact with living tissue. In our study, the M3DGAs developed a granulomatous chronic inflammatory response, represented by macrophages and multinuclear giant cells, different from the inflammatory response seen in the control group. Similar appearances were found in the three experimental groups (GA1, GA2, and GA3) at all biological points, exhibiting regressive evolution characteristics associated with the degradation of the collagen and elastic fibers of the M3DGAs under analysis (Fig. 4). It is worth emphasizing that, in GA2, in addition to the granulomatous inflammation, discreet regressive lymphocytic inflammatory leakage was noted at the three biological points (Fig. 5). Such response was qualitatively similar to that found by Goissis et al., ${ }^{4}$ when they studied the biocompatibility and biodegradation of the anionic collagen membranes exposed to different periods $(8$, 22 , and $28 \mathrm{~h}$ ) cross-linked in GA and implanted sub-cutaneously in rats. However, in this study, inflammation and an amount of degradation of the collagen fibers was observed

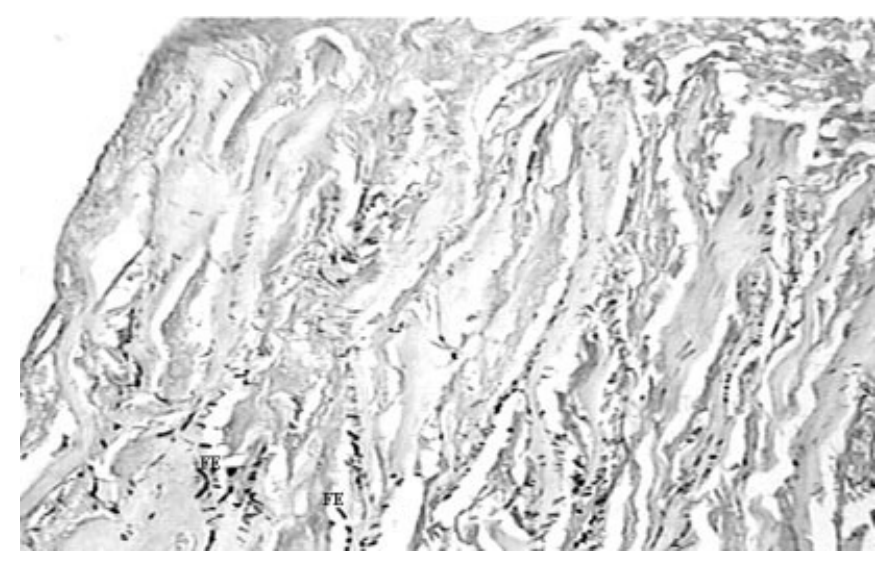

Figure 4. GA1 30D. Fragmented elastic fibers (FE) in the non-mineralized areas. Note their absence in the mineralized areas. ORCE. Final enlargement $\times 700$.

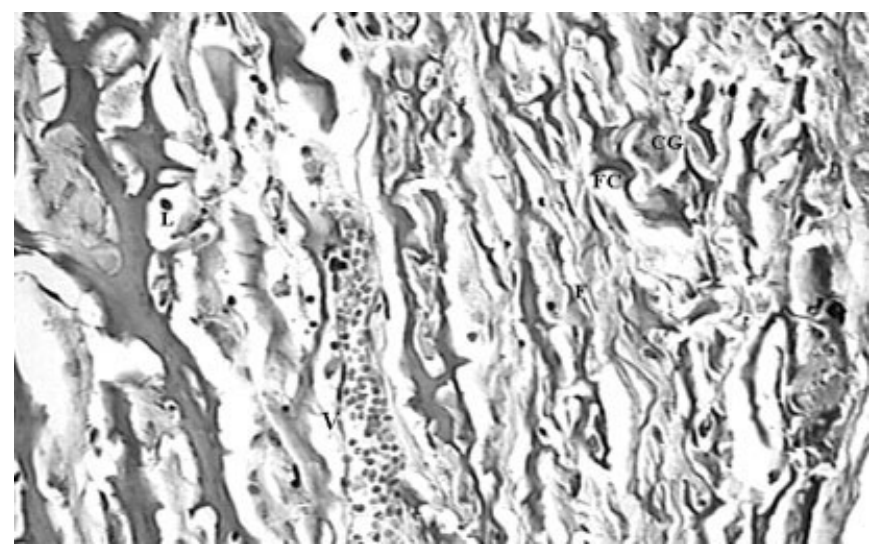

Figure 5. GA2 60D. Mild lymphocytic inflammatory leakage seen in the midst of the fibers. Giant cell (CG), fibroblast (F), collagen fiber $(F C)$, lymphocyte $(L)$, vessel $(V)$. H.E. Final enlargement $\times 700$.

with greater intensity in relation to the lower cross-linked time of the membranes in GA, which was not shown in our study.

Yet, these results contradict those presented by Rocha et al., ${ }^{16}$ which implanted the biomaterials on small bone defect created in rat tibia, and Rosa et al., ${ }^{9}$ who showed that hydrolyzed three-dimensional collagenic/anionic matrices (M3Ds) not cross-linked in GA implanted over calvaria in contact with the bone, did not induce any inflammatory response; these matrices were whole when not yet integrated in the mineralization areas. Apparently, the different results with regard to inflammation and amount of fiber degradation/ absorption were the result of the methodological differences used in these studies, specifically, differences between the implantation sites and physical-chemical characteristics of the biomaterials, such as those cross-linked in GA. Thus, our data indicated that this treatment led to the granulomatous chronic inflammatory response.

The use of critical defects measuring $8 \mathrm{~mm}$ in bone regeneration studies is most suitable, since, in bone defects with smaller dimensions $(5$ or $6 \mathrm{~mm}$ ) the remaining residual area may present complete bone regeneration only with the use of osteoconductor biomaterials. ${ }^{17-19}$ However, the osteoconductor mechanism presents reparative limitations that may not favor the complete regeneration of defects measuring $8 \mathrm{~mm}$. In addition to the osteoconductor characteristic, it is necessary for the biomaterial to be osteostimulator and inductor. In our work, we observed neomineralization areas present in the midst of the implanted matrix fibers in the central area of the defects. We believe this might be due to the presence of osteostimulator and inductor components, as well as the osteoconductors inherent in these biomaterials, but these properties weren't measured in our study.

The neomineralization present among the M3DGA's fibers was favored by cross-linking in the GA as well as by hydrolysis. When the BP is cross-linked in the GA, some factors, such as the presence of phospholipids in tissue or cavities, created by the removal of proteoglycans during processing or cellular degradation are predisposed to nucle- 
TABLE I. Total Neoformed Mineralized Sectional Area $\left(\mu \mathrm{m}^{2}\right)$ According to Period (days) and Group

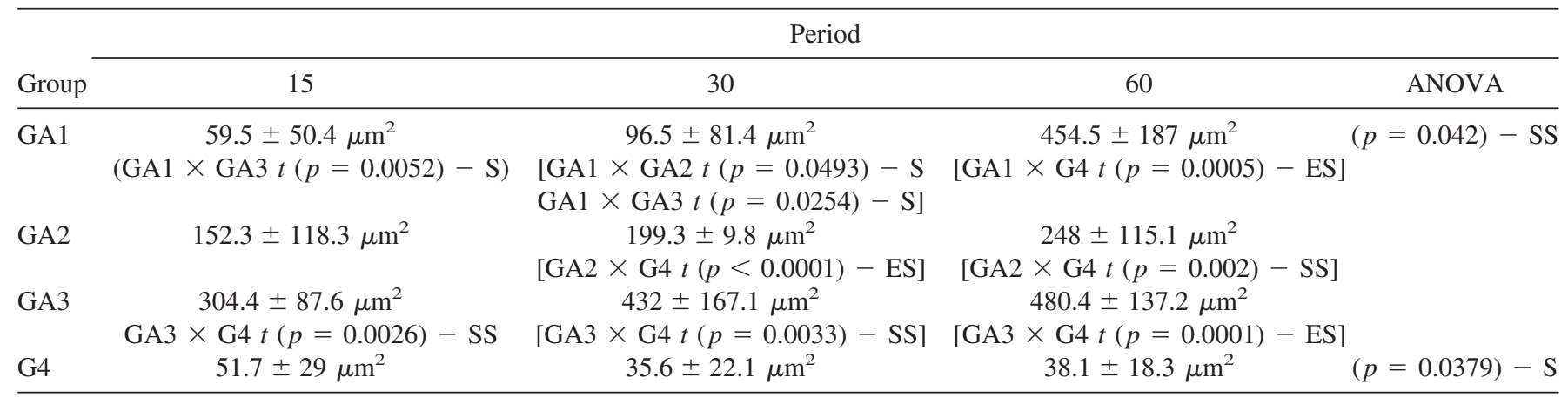

GA1-M3DGA-60 min of cross-linking; GA2-M3DGA-30 min of cross-linking; GA3-M3DGA-15 min of cross-linking; G4 without any implanted biomaterial; $t$-Student, ANOVA, one-way analysis of variance; NS, not statistically significant; S, statistically significant; SS, stronger statistically significant; ES, extremely statistically significant.

ation centers for calcium. ${ }^{3}$ Increased calcium uptake leads to a build-up of calcium phosphate, which in time mineralizes into calcium hydroxyapatite. ${ }^{3}$ The hydrolysis increases the electrostatic interaction between the cationic center and the gap-overlap junction, modifying the conformation of the hydrophobic barrier present between the fibers, capable of preventing calcium ion migration in this region. ${ }^{8}$ Thus, the spatial conformation of the fiber bundles of the matrices enabled the angiogenesis as well as the migration, adhesion, and progressive proliferation of the undifferentiated mesenchymal fusiform cells in the three groups: GA1, GA2, and GA3. According to Goissis et al., ${ }^{8}$ the mineral deposition present in these matrices occurs both in vitro and in vivo, and they are morphologically and chemically similar. In vivo, this deposition occurs in the gap-overlap junction region of the collagen fibers; similar to that produced in the collagen fibers resulting from osteoblastic activity during the reconstruction of the bone tissue. This suggests the biomimetic behavior is similar to that of the M3DGA, with respect to calcium phosphate deposition.

The morphometric measurements of the total neoformed mineralized sectional area (Table I) showed statistically significant differences among the groups (GA1, GA2, and GA3)

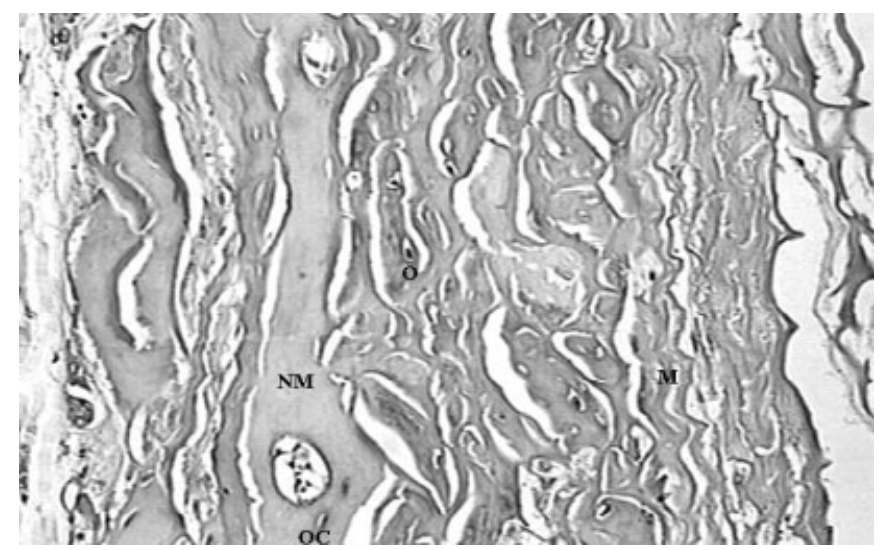

Figure 6. GA1 60D. Nuclei of mineralization among the M3DGA (M) fibers. Mineralization nuclei (NM), osteoblast (O), osteocyte (OC), (V). H.E. Final enlargement $\times 700$. in relation to G4. After day 60 , by the $t$ test, one was able to note the following values GA1 ( $p=0.0005-\mathrm{ES}), \mathrm{GA} 2$ ( $p=$ $0.0002-\mathrm{SS})$, and GA3 ( $p=0.0001-\mathrm{ES})$, where a mean with greater value is outstanding for GA3. These data show evidence of an intensification of neoformation, probably due to the presence of osteostimulator and inductor components, as well as the osteoconductors inherent in the M3DGAs. Mineralization in plate form was observed predominantly in the portion of the biomaterial close to the dura-mater at the beginning of neoformation and maintained in the other subsequent periods in the three groups (GA1, GA2, and GA3), but to a greater extent (Fig. 6-8). Pointing out GA1, in which it was possible to identify mineral deposition in juxtaposition to the M3DGA fibers and GA3 seen with frequently confluent areas. The percentage of linear filling of the defects by neoformed mineralized tissue (Table II) showed, by $\chi^{2}$, statistically significant difference when the three groups (GA1, GA2, and GA3) were compared with G4.

Associated with neomineralization present in the midst of the implanted matrix fibers, the progressive deposition of the extracellular matrix was observed at all biological points, mainly glicosaminoglycan (GAGs). At day 60, these were noted throughout the complete extent of the material. In GA3, the deposition of these was seen even in the interstice (Fig. 9).

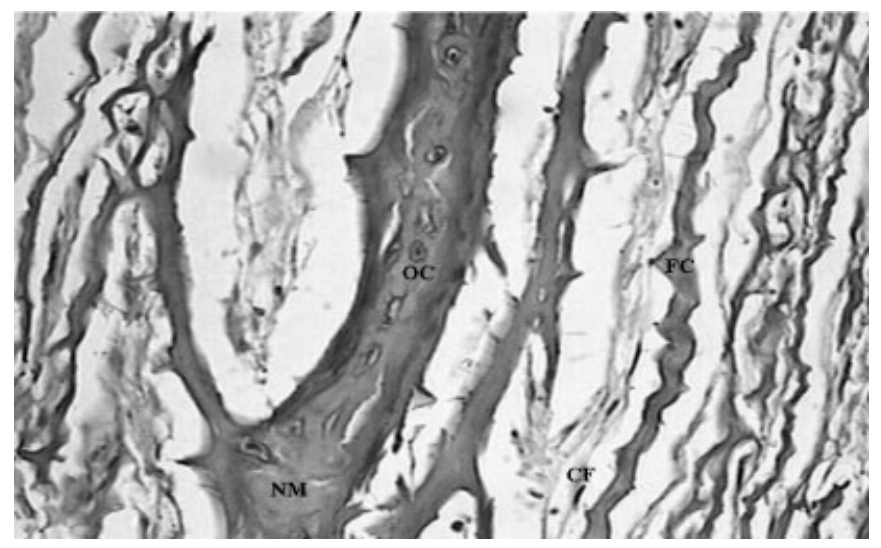

Figure 7. GA2 60D. Nucleus of mineralization in organization among the M3DGA fibers. Fusiform cell (CF), collagen fiber $(F C),(O),(O C)$, (NM). H.E. Final enlargement $\times 700$. 


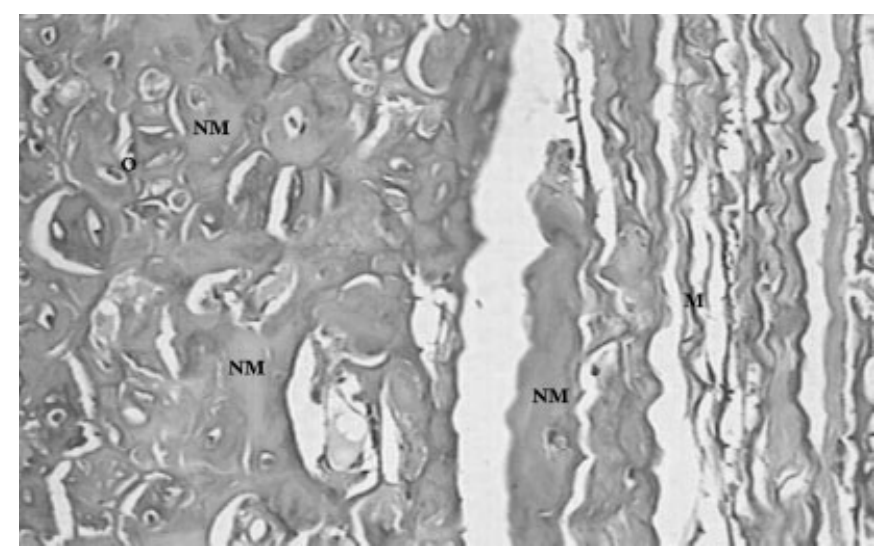

Figure 8. GA3 60D. Areas of confluent mineralization among the M3DGA fibers in the supra-dural region. (M), (NM), (O). H\&E final enlargement, $\times 700$.

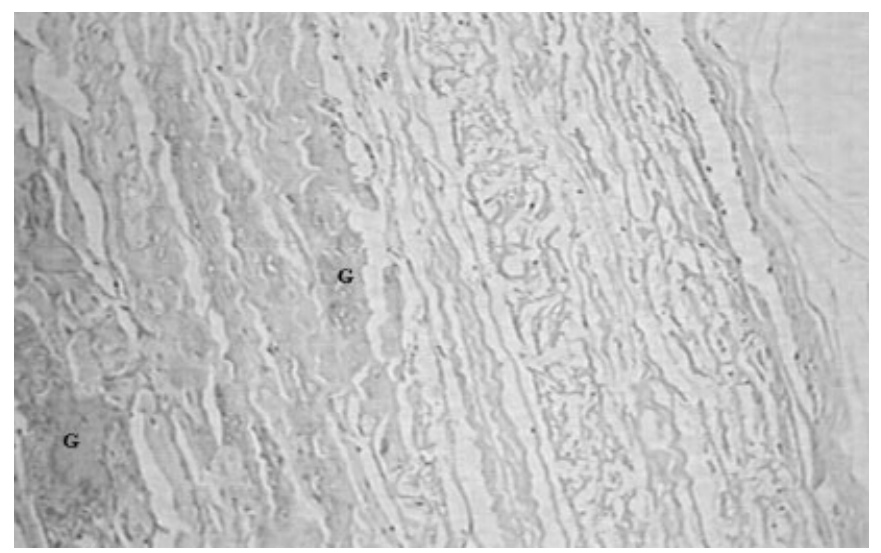

Figure 9. GA3 60D. Deposition of glicosaminoglycan (G) in the mineralization areas. A.A. final enlargement, $\times 400$.

TABLE II. Linear Extension of Primary Defect $(\mathrm{mm})$ and Percentage of Linear Filling by Neoformed Mineralized Tissue (\%) According to Period (days) and Group

\begin{tabular}{lcccc}
\hline & & & Period \\
\cline { 2 - 5 } Group & 15 & 30 & 60 & \\
\hline G A1 & $5.9 \pm 1.1(\mathrm{~mm})$ & $6.5 \pm 0.2(\mathrm{~mm})$ & $6.2 \pm 1.5(\mathrm{~mm})$ & $\chi^{2} \mathrm{GA} 1 \times \mathrm{GA} 2(p=0.25119) \mathrm{NS}$ \\
& $8.0 \pm 4(\%)$ & $30.1 \pm 20(\%)$ & $39.6 \pm 37(\%)$ & $\begin{array}{l}\chi^{2} \mathrm{GA} 1 \times \mathrm{GA} 3(p=0.01362) \mathrm{S} \\
\chi^{2} \mathrm{GA} 1 \times \mathrm{G} 4(p=0.00230) \mathrm{SS}\end{array}$ \\
G A2 & $6.6 \pm 1.3(\mathrm{~mm})$ & $6.0 \pm 0.7(\mathrm{~mm})$ & $6.3 \pm 0.6(\mathrm{~mm})$ & $\chi^{2} \mathrm{GA} 2 \times \mathrm{GA} 3(p=0.61813) \mathrm{NS}$ \\
& $7.0 \pm 3(\%)$ & $15.9 \pm 8(\%)$ & $39.9 \pm 10(\%)$ & $\chi^{2} \mathrm{GA} 2 \times \mathrm{G} 4(p=0.00090) \mathrm{ES}$ \\
G A3 & $6.2 \pm 0.3(\mathrm{~mm})$ & $5.1 \pm 0.6(\mathrm{~mm})$ & $5.3 \pm 0.3(\mathrm{~mm})$ & $\chi^{2} \mathrm{GA} 3 \times \mathrm{G} 4(p<0.00001) \mathrm{ES}$ \\
& $11.2 \pm 4(\%)$ & $24 \pm 11(\%)$ & $84 \pm 15(\%)$ & ANOVA \\
G 4 & $6.8 \pm 1.3(\mathrm{~mm})$ & $6.0 \pm 2(\mathrm{~mm})$ & $6.8 \pm 1.6(\mathrm{~mm})$ & Extension $(p=0.1568)-\mathrm{NS}$ \\
& $16.7 \pm 10(\%)$ & $17.3 \pm 13(\%)$ & $15 \pm 4(\%)$ & $\chi^{2}$ \\
& & & & Percentage $(p<0.00001)-\mathrm{ES}$ \\
\hline
\end{tabular}

GA1-M3DGA-60 min of cross-linking; GA2-M3DGA-30 min of cross-linking; GA3-M3DGA-15 min of cross-linking; G4 without any implanted biomaterial. $\chi^{2}$, chi-square; ANOVA, one-way analysis of variance; NS, not statistically significant; S, statistically significant; SS, stronger statistically significant; ES, extremely statistically significant.

\section{CONCLUSION}

Under the experimental conditions of this study, the M3DGAs of the groups GA1, GA2, and GA3 were biocompatible, only mild and regressive chronic inflammation being observed. In these groups, the defect was filled by neomineralized tissue at day 60 , with very statistically significant mean values in relation to the control group. Thus, this work has shown that matrices are a biomaterial for repairing critical size bone defects and that controlled biodegradation may be achieved as a function of the time of GA exposure. According to the parameters observed, the M3DGAs presented more accentuated neomineralization for GA3 (M3DGA $15 \mathrm{~min}$ ). However, the longer the period of cross-linking time, the more extended is the permanence of this biomaterial in the implantation site. Our results indicated not only the biomimetic behavior of M3DGA, but they also gave some insight as to potential future uses of M3DGA as a scaffold for bone tissue reconstruction. However, another more in-depth study as to specific uses of M3DGA should be undertaken to confirm this hypothesis.

\section{REFERENCES}

1. Goissis G, Piccirili L, Goes JC, Plepis AMG, Das-Gupta DK. Anionic collagen: polymer composites with improved dielectric and rheological properties. Artif Organs 1998;22:203-209.

2. Rho JY, Kuhn-Spearing L, Zioupos P. Mechanical properties and the hierarchical structure of bone. Med Eng Phys 1998;20: 92-102.

3. Khor E. Methods for the treatment of collagenous tissues for bioprotheses. Biomaterials 1997;18:95-105.

4. Goissis G, Marcantonio E Jr, Marcantonio RAC, Lia RCC, Cancian DCJ, Carvalho WM. Biocompatibility studies of anionic collagen membranes with different degree of glutaraldehyde cross-linking. Biomaterials 1999;20:27-34.

5. Jorge-Herrero E, Fernández $\mathrm{P}$, Turnay J, Olmo N, Calero P, García R, Freile I, Castillo-Olivares JL. Influence of different chemical cross-link treatments on the properties of bovine pericardium and collagen. Biomaterials 1999;20:539-545. 
6. Góes JC, Figueiró SD, Paiva JAC. Vasconcelos IF, Sombra ASB. On the piezoelectricity of anionic collagen films. J Physics Chemistry Solids 2002;63:465-470.

7. Bet MR, Goissis G, Lacerda CA. Characterization of polyanionic collagen prepared by selective hydrolysis of aspargine and glutamine carboxyamide side chains. Biomacromolecules 2001; 2:1074-1079.

8. Goissis G, Maginador SVS, Martins VCA. Biomimetic mineralization of charged collagen matrices: in vitro and in vivo study. Artif Organs 2003;27:437-443.

9. Rosa FP, Lia RCC, Souza KOF, Goissis G, Marcantonio E Jr. Tissue response to polyanionic collagen: elastin matrices implanted in rat calvaria. Biomaterials 2003;24:207-212.

10. Takagi K, Urist MR. The reaction of the dura to bone morphogenetic protein (BMP) in repair of skull defects. Ann Surg 1982;196:100-109.

11. Schmitz JP, Hollinger JO. The critical size defect as an experimental model for craniomandibulofacial nonunions. Clin Orthop 1986;205:299-308.

12. Sweeney TM, Opperman LA, Persing JA, Ogle RC. Repair of critical size rat calvarial defects using extracellular matrix protein gels. J Neurosurg 1995;83:710-714.

13. Chesmel KD, Branger J, Wertheim H, Scarborough N. Healing response to various forms of human demineralized bone matrix in athymic rat cranial defects. J Oral Maxillofac Surg 1998;56: 857-863.

14. O'brien FJ, Harley BA, Yannas IV, Gibson LJ. The effect of pore size on cell adhesion in collagen-GAG sacffolds. Biomaterials 2005;26:433-441.

15. Rosa FP. Resposta tecidual de matrizes de pericárdio bovino, submetidas a diferentes tratamentos químicos, implantadas sobre calvária de ratos. 2001. Tese Doutorado, Faculdade de Odontologia de Araraquara, Universidade Estadual Paulista, Araraquara - SP.

16. Rocha LB, Goissis G, Rossi MA. Biocompatibility of anionic collagen matrix as scaffold for bone healing. Biomaterials 2002; 23:449-456.

17. Bosch C, Melsen B, Vargervik K. Guided bone regeneration in calvarial bone defects using polytetrafluorethylene membranes. Cleft Palate-Craniofac J 1995;32:311-317.

18. Bosch C, Melsen B, Vargervik K. Importance of the critical-size bone defect in testing bone-regeneration materials. J Craniofac Surg 1998;9:310-316.

19. Brunel G, Piantoni P, Elharar F, Benqué E, Marin P, Zahedi S. Regeneration of rat calvarial defects using a bioabsorbable membrane technique: influence of collagen cross-linking. J Periodontol 1996;67:1342-1348.

20. Tiller JC, Bonner G, Pan L C, Klibanov AM. Improving biomaterial properties of collagen films by chemical modification. Biotechnol Bioeng. 2001;73:246-252. 